\title{
The effect of asymmetries on optimal hedge ratios
}

Article

Accepted Version

Brooks, C., Henry, O.T. and Persand, G. (2002) The effect of asymmetries on optimal hedge ratios. Journal of Business, 75 (2). pp. 333-352. ISSN 0740-9168 Available at https://centaur.reading.ac.uk/24151/

It is advisable to refer to the publisher's version if you intend to cite from the work. See Guidance on citing.

Published version at: http://ideas.repec.org/a/ucp/jnlbus/v75y2002i2p333-352.html

Publisher: University of Chicago Press

All outputs in CentAUR are protected by Intellectual Property Rights law, including copyright law. Copyright and IPR is retained by the creators or other copyright holders. Terms and conditions for use of this material are defined in the End User Agreement.

\section{www.reading.ac.uk/centaur}

\section{CentAUR}

Central Archive at the University of Reading

Reading's research outputs online 
This is the authors' accepted manuscript of an article published in the Journal of Business. The definitive version is available at:

http://www.jstor.org/page/journal/jbusiness/about.html 


\title{
The Effect of Asymmetries on Optimal Hedge
}

\section{Ratios $^{*}$}

Chris Brooks

The ISMA Centre, Department of Economics, University of Reading

\author{
Ólan T. Henry
}

Department of Economics, University of Melbourne,

\section{Gita Persand}

The ISMA Centre, Department of Economics, University of Reading 


\begin{abstract}
There is widespread evidence that the volatility of stock returns displays an asymmetric response to good and bad news. This paper considers the impact of asymmetry on time varying hedges for financial futures. An asymmetric model which allows forecasts of cash and futures return volatility to respond differently to positive and negative return innovations gives superior in-sample hedging performance. However, the simpler symmetric model is not inferior in a hold-out sample. A method for evaluating the models in a modern risk management framework is presented, highlighting the importance of allowing optimal hedge ratios to be both time-varying and asymmetric.
\end{abstract}




\section{Introduction}

Over the past two decades, increases in the availability and usage of derivative securities has allowed agents who face price risk the opportunity to reduce their exposure. Although there are many techniques available for reducing and managing risk, the simplest and perhaps the most widely used, is hedging with futures contracts. A hedge is achieved by taking opposite positions in spot and futures markets simultaneously, so that any loss sustained from an adverse price movement in one market should to some degree be offset by a favourable price movement in the other. The ratio of the number of units of the futures asset that are purchased relative to the number of units of the spot asset is known as the hedge ratio.

Since risk in this context is usually measured as the volatility of portfolio returns, an intuitively plausible strategy might be to choose that hedge ratio which minimises the variance of the returns of a portfolio containing the spot and futures position; this is known as the optimal hedge ratio. There has been much empirical research into the calculation of optimal hedge ratios (see, for example, Cecchetti et al., 1988; Myers and Thompson, 1989; Baillie and Myers, 1991; Kroner and Sultan, 1991; Lien and Luo, 1993; Lin et al., 1994; Strong and Dickinson, 1994; Park and Switzer, 1995).

The general consensus is that the use of multivariate generalised autoregressive conditionally heteroscedastic (MGARCH) models yields superior performances evidenced by lower portfolio volatilities, than either time-invariant or rolling ordinary least squares (OLS) hedges. Cecchetti et al (1988), Myers and Thompson (1989) and Baillie and Myers (1991), for example, argue that commodity prices are characterised by time-varying 
covariance matrices. As news about spot and futures prices arrives to the market, the conditional covariance matrix, and hence the optimal hedging ratio, becomes time-varying. Baillie and Myers (1991) and Kroner and Sultan (1993), inter alia, employ MGARCH models to capture time-variation in the covariance matrix and the resulting hedge ratio.

On the other hand, there is also evidence that the benefits of a time varying hedge are substantially diminished as the duration of the hedge is increased (e.g Lin et al., 1994). Moreover, there is evidence that the use of volatility forecasts implied by options prices can further improve hedging effectiveness (Strong and Dickinson, 1994).

This paper has three main aims. Firstly, we link the concept of the optimal hedge with the notion of the News Impact Surface of Kroner and $\mathrm{Ng}$ (1998). The hedging surface of the OLS model is independent of news arriving to the market and therefore could be sub-optimal. Secondly, we extend the models of Cecchetti et al (1988), Myers and Thompson (1989) and Baillie and Myers (1991) to allow for time variation and asymmetry across the entire variance covariance matrix of returns. This means that the hedge ratio will be sensitive to the size and sign of the change in prices resulting from information arrival. Thirdly, we adapt the methods used by Hsieh (1993) to show how the effectiveness of hedges can be evaluated by the calculation of minimum capital risk requirements (MCRRs). Such a procedure allows the hedging performance of the various models to be assessed using a relevant economic loss function as well as on pure statistical grounds.

The paper is laid out in six sections. Section two presents the theoretical framework for deriving the hedge ratios, while section three 
describes the data. Section four presents the empirical evidence on the performance of each hedging model, while the fifth section outlines the bootstrap methodology used to calculate the MCRR for each of the portfolios. Section six concludes.

\section{The Derivation of Optimal Hedge Ratios}

Let $C_{t}$ and $F_{t}$ represent the logarithms of the stock index and stock index futures prices respectively. The actual return on a spot position held from time $t-1$ to $t$ is $\Delta C_{t}=C_{t}-C_{t-1}$ similarly, the actual return on a futures position is $\Delta F_{t}=F_{t}-F_{t-1}$. However, at time $t-1$, the expected return, $E_{t-1}\left(R_{t}\right)$, of the portfolio comprising one unit of the stock index and $\beta$ units of the futures contract may be written as

$$
E_{t-1}\left(R_{t}\right)=E_{t-1}\left(\Delta C_{t}\right)-\beta_{t-1} E_{t-1}\left(\Delta F_{t}\right)
$$

where $\beta_{t-1}$ is the hedge ratio determined at time $t-1$, for employment in period $t{ }^{1}$ The variance of the portfolio may be written as

$$
h_{p, t}=h_{C, t}+\beta_{t-1}^{2} h_{F, t}-2 \beta_{t-1} h_{C F t}
$$

where $h_{p, t}, h_{F, t}$ and $h_{C, t}$ represent the conditional variances of the portfolio and the spot and futures positions respectively and $h_{C F, t}$ represents the conditional covariance between the spot and futures position. If the agent has the two moment utility function

$$
U\left(E_{t-1} R_{t}, h_{p, t}\right)=E_{t-1}\left(R_{t}\right)-\psi h_{p, t}
$$

then the utility maximising agent with degree of risk aversion $\psi$ seeks to solve

$$
\begin{aligned}
& \max U\left(E_{t-1} R_{t}, h_{p, t}\right)= \\
& E_{t-1}\left(\Delta C_{t}\right)-\beta_{t-1} E_{t-t}(\Delta F)-\psi\left(h_{C, t}+\beta_{t-1}^{2} h_{F, t}-2 \beta_{t-1} h_{C F, t}\right)
\end{aligned}
$$


Solving (4) with respect to $\beta$ under the assumption that $F_{t}$ is a martingale process such that $E_{t-1}\left(\Delta F_{t}\right)=E_{t-1}\left(F_{t}\right)-F_{t-1}=F_{t-1}-F_{t-1}=0$ yields $\beta_{t-1}^{*}$, the optimal number of futures contracts in the investor's portfolio

$$
\beta_{t-1}^{*}=-\frac{h_{C F, t}}{h_{F, t}}
$$

If the conditional variance-covariance matrix is time-invariant (and if $C_{t}$ and $F_{t}$ are not cointegrated) then an estimate of $\beta^{*}$, the constant optimal hedge ratio, may be obtained from the estimated slope coefficient $b$ in the regression

$$
\Delta C_{t}=a+b \Delta F_{t}+u_{t}
$$

The OLS estimate of $b=h_{C F} / h_{F}$ is also valid for the multiperiod hedge in the case where the investors utility function is time separable.

However, it has been shown by numerous studies (see section 1 above) that the data do not support the assumption that the variance-covariance matrix of returns is constant over time. Therefore we follow recent literature by employing a bivariate GARCH model which allows the conditional variances and covariances used as inputs to the hedge ratio to be time-varying.

In the absence of transactions costs, market microstructure effects or other impediments to their free operation, the efficient markets hypothesis and the absence of arbitrage opportunities implies that the spot and corresponding futures markets react contemporaneously and identically to new information. There has been some debate in the literature as to whether this implies that the two markets must be cointegrated. Ghosh (1993), for example, suggests that market efficiency should imply that cash and futures are cointegrated, while Baillie and Myers (1991) suggest that, as a consequence of possible nonstationarity of the risk free proxy employed in the cost of carry model, this 
need not be the case. We do not wish to enter into this debate from a theoretical viewpoint, but suffice to say that in all ensuing analysis, we allow for, but do not impose, a [-1 1] cointegrating vector for the two series. The conditional mean equations of the model employed in this paper are a bivariate Vector Error Correction Mechanism (VECM), which may be written as

$$
\begin{aligned}
& \Delta Y_{t}=\mu+\sum_{i=1}^{4} \Gamma_{i} \Delta Y_{t-i}+\Pi v_{t-1}+\varepsilon_{t} \\
& Y_{t}=\left[\begin{array}{l}
F_{t} \\
C_{t}
\end{array}\right] ; \mu=\left[\begin{array}{l}
\mu_{F} \\
\mu_{C}
\end{array}\right] ; \Gamma_{i}=\left[\begin{array}{ll}
\Gamma_{i, F}^{(F)} & \Gamma_{i, C}^{(F)} \\
\Gamma_{i, F}^{(C)} & \Gamma_{i, C}^{(C)}
\end{array}\right] ; \pi=\left[\begin{array}{l}
\pi_{F} \\
\pi_{C}
\end{array}\right] ; \varepsilon_{t}=\left[\begin{array}{l}
\varepsilon_{F, t} \\
\varepsilon_{C, t}
\end{array}\right]
\end{aligned}
$$

Under the assumption $\varepsilon_{t} \mid \Omega_{t} \sim\left(0, H_{t}\right)$, where $\varepsilon_{t}$ represents the innovation vector in (6) and defining $h_{t}$ as vech $\left(H_{t}\right)$, where vech(.) denotes the vector-half operator that stacks the lower triangular elements of an $N \times N$ matrix into an $(N(N+1) / 2) \times 1$ vector, the bivariate $\operatorname{VECM}(p) \operatorname{GARCH}(1,1)$ vech model may be written

$$
\operatorname{vec}\left(H_{t}\right)=h_{t}=\left[\begin{array}{c}
h_{C, t} \\
h_{C F, t} \\
h_{F, t}
\end{array}\right]=C_{0}+A_{1} \operatorname{vec}\left(\varepsilon_{t-1} \varepsilon_{t-1}{ }^{\prime}\right)+B_{1} h_{t-1}
$$

where

$$
C_{0}=\left[\begin{array}{l}
c_{11} \\
c_{12} \\
c_{22}
\end{array}\right] ; \quad A_{1}=\left[\begin{array}{lll}
a_{11} & a_{12} & a_{13} \\
a_{21} & a_{22} & a_{23} \\
a_{31} & a_{32} & a_{33}
\end{array}\right] ; \quad B_{1}=\left[\begin{array}{lll}
b_{11} & b_{12} & b_{13} \\
b_{21} & b_{22} & b_{23} \\
b_{31} & b_{32} & b_{33}
\end{array}\right]
$$

Restricting the matrices $A_{1}$ and $B_{1}$ to be diagonal gives the model proposed by Bollerslev, Engle and Wooldridge (1988) where each element of the conditional variance-covariance matrix $h_{i j, t}$ depends on past values of itself and past values of $\varepsilon_{t-1} \varepsilon_{t-1}^{\prime}$. There are 21 parameters in the conditional 
variance-covariance structure of the bivariate $G A R C H(1,1)$ vech model (8) to be estimated, subject to the requirement that $H_{t}$ be positive definite for all values of $\varepsilon_{t}$ in the sample. The difficulty of checking, let alone imposing such a restriction led Engle and Kroner (1995) to propose the BEKK parameterisation

$$
H_{t}=C_{0}^{*{ }^{*}} C_{0}^{*}+A_{11}^{* \prime} \varepsilon_{t-1} \varepsilon_{t-1}^{\prime} A_{11}^{*}+B_{11}^{* \prime} H_{t-1} B_{11}^{*}
$$

The BEKK parameterisation requires estimation of only 11 parameters in the conditional variance-covariance structure and guarantees $H_{t}$ positive definite. It is important to note that the BEKK and vec models imply that only the magnitude of past return innovations is important in determining current conditional variances and covariances. This assumption of symmetric timevarying variance-covariance matrices must be considered tenuous given the existing body of evidence documenting the asymmetric response of equity volatility to positive and negative innovations of equal magnitude (see Engle and $\mathrm{Ng}$, 1993, Glosten, Jagannathan and Runkle, 1993, and Kroner and Ng, 1998, inter alia).

Defining $\xi_{j, t}=\min \left\{\varepsilon_{t}, 0\right\}$, for $j=$ futures, cash, the BEKK model in (9) may be extended to allow for asymmetric responses as

$$
H_{t}=C_{0}^{* \prime} C_{0}^{*}+A_{11}^{* \prime} \varepsilon_{t-1} \varepsilon_{t-1}^{\prime} A_{11}^{*}+B_{11}^{* \prime} H_{t-1} B_{11}^{*}+D_{11}^{* \prime} \xi_{t-1} \xi_{t-1}^{\prime} D_{11}^{*}
$$

where 


$$
\begin{array}{rlr}
C_{0}^{*}=\left[\begin{array}{ll}
c_{11}^{*} & c_{12}^{*} \\
0 & c_{22}^{*}
\end{array}\right] ; & A_{11}^{*}=\left[\begin{array}{ll}
\alpha_{11}^{*} & \alpha_{12}^{*} \\
\alpha_{11}^{*} & \alpha_{22}^{*}
\end{array}\right] ; \\
B_{11}^{*}=\left[\begin{array}{ll}
\beta_{11}^{*} & \beta_{12}^{*} \\
\beta_{11}^{*} & \beta_{22}^{*}
\end{array}\right] ; & D_{11}^{*}=\left[\begin{array}{ll}
\delta_{11}^{*} & \delta_{12}^{*} \\
\delta_{11}^{*} & \delta_{22}^{*}
\end{array}\right]
\end{array}
$$

The symmetric $B E K K$ model (9) is given as a special case of (10) for $\delta_{m, n}=0$, for all values of $m$ and $n$.

\section{Data Description}

The data employed in this study comprises 3580 daily observations on the FTSE 100 stock index and stock index futures ${ }^{2}$ contract spanning the period 1 January 1985 - 9 April 1999. Days corresponding to UK public holidays are removed from the series to avoid the incorporation of spurious zero returns.

The FTSE 100 comprises the 100 UK companies quoted on the London Stock Exchange with the largest market capitalisation, accounting for $73.2 \%$ of the market value of the FTSE All Share Index as at 29 December 1995 (Sutcliffe 1997). FTSE 100 futures contracts are quoted in the same units as the underlying index, except that the decimal is rounded to the nearest $0.5^{3}$. The price of a futures contract (contract size) is the quoted number (measured in index points) multiplied by the contract multiplier, which is $£ 25$ for the contract. There are four delivery months: March, June, September and December. Trading takes place in the three nearest delivery months although volume in the 'far' contract is very small. Each contract is therefore traded for nine months. FTSE100 futures contracts are cash-settled as opposed to physical delivery of the underlying. All contracts are marked to market on the last trading day, which is the third Friday in the delivery month, at which point 
all positions are deemed closed. For the FTSE100 futures contract, the settlement price on the last trading day is calculated as an average of minuteby-minute observations between 10:10AM and 10:30AM rounded to the nearest 0.5.

Summary statistics for the data are displayed in panel A of table 1. Using Dickey Fuller (1979) unit root tests, it is not possible to reject the null hypothesis of non-stationarity for the cash and futures price series. This nonstationarity of the price series is consistent with weak-form efficiency of the cash and futures markets. The return series are calculated as $100 \times\left(C_{t} / C_{t-1}\right)$ and $100 \times\left(F_{t} / F_{t-1}\right)$, respectively. The returns are skewed to the left, leptokurtic and stationary. These features are entirely in accordance with expectations and results presented elsewhere. In the absence of a long run relationship between $C_{t}$ and $F_{t}$, optimal inference based upon asymptotic theory requires the use of returns rather than price data in calculation of estimation of dynamic hedge ratios.

Results for both Engle-Granger (1987) and Johansen (1988) tests for cointegration are displayed in table 1.The Engle-Granger results of panel B clearly demonstrate that the null of non-stationarity in the residuals of the cointegrating regression is strongly rejected, for the test both with and without a constant term. Moreover the estimated slope coefficient is very close to unity whether the spot or futures price is the dependent variable. Similarly, the Johansen test statistics, for both the trace and the max forms, reject the null of no cointegrating vector, but do not reject the null of one cointegrating vector. A restriction of the cointegrating relationship between the series to be [1 -1] was marginally rejected at the 5\% level. However, after normalising the 
estimated cointegration vector on $C_{t}$, the estimated coefficient on $F_{t}$ was 1.006 suggesting that this rejection may not be economically important. On close examination of the short run components of the VECM it appears that the futures prices are weakly exogenous. A likelihood ratio test supports this restriction. Thus while the cointegrating equilibrium is defined by both cash and futures prices, equilibrium is restored through the cash markets. A test of the joint hypothesis that futures prices are weakly exogenous and that the parameters of the cointegration vector are $[1,-1]$ was not rejected at the $5 \%$ level of significance. Baillie and Myers (1991) argue that a perfect 1:1 association does not exist in a commodity futures hedge due to the cost of carry, although this does not preclude some other cointegrating relationship from existing. On balance, the data appear to be cointegrated with a $[1,-1]$ cointegrating vector.

\section{Hedging Model Estimates, Tests and Performance}

Given the evidence of a long-run or cointegrating relationship between $C_{t}$ and $F_{t}$ the conditional mean equations are parameterised as a VECM rather than a VAR to avoid loss of long run information.

The parameter estimates and associated residual diagnostics for the multivariate asymmetric GARCH model are presented in table 2. Again, the factor loading associated with the futures prices is positive indicating that the return to equilibrium is achieved via the cash markets. A high degree of persistence is variance in indicated in both markets. The persistence is measured by $\alpha_{i i}^{2}+\beta_{i i}^{2}$ for $i=1,2$. The statistical significance of the elements of 
the $D_{11}^{*}$ matrix indicates the presence of asymmetries in the variancecovariance matrix.

Kroner and $\mathrm{Ng}$ (1998) analyse the asymmetric properties of timevarying covariance matrix models, identifying three possible forms of asymmetric behaviour. Firstly, the covariance matrix displays own variance asymmetry if $h_{C, t}\left(h_{F, t}\right)$, the conditional variance of $C_{t}\left(F_{t}\right)$, is affected by the sign of the innovation in $C_{t}\left(F_{t}\right)$. Secondly, the covariance matrix displays cross variance asymmetry if the conditional variance of $C_{t}\left(F_{t}\right)$ is affected by the sign of the innovation in $F_{t}\left(C_{t}\right)$. Finally if the covariance of returns $h_{C F, t}$ is sensitive to the sign of the innovation in return for either $C_{t}$ or $F_{t}$ then the model is said to display covariance asymmetry.

The residual diagnostics indicate that the model was able to capture all of the dependence on past values in both the conditional mean and conditional variances for both the spot and futures equations. The coefficients of skewness and excess kurtosis are much reduced relative to their values on the raw data, again indicating a reasonable fit of the model to the two series. The robust likelihood ratio tests suggested by Kroner and $\mathrm{Ng}$ (1998) to detect such asymmetry in MGARCH models indicate that the asymmetric model provides a superior data characterisation to the symmetric $\operatorname{MGARCH}(1,1)$. The final row of table 2 tests the restriction of the asymmetric model to be symmetric; that is, a restriction that good and bad news affect the volatility of the spot and futures markets equally. This restriction is clearly rejected, suggesting that the pursuit of an asymmetric model is important and may yield superior hedging 
performance relative to a model which ignores this feature which is manifest in the data.

The price innovations, $C_{t}-C_{t-1}=\varepsilon_{C, t}$ and $F_{t}-F_{t-1}=\varepsilon_{F, t}$, represent changes in information available to the market (ceteris paribus). Kroner and $\mathrm{Ng}$ (1998) treat such innovations as a collective measure of news arriving to market $j$ between the close of trade on period $t-1$ and the close of trade on period $t$. They define the relationship between innovations in return and the conditional variance-covariance structure as the news impact surface, a multivariate form of the news impact curve of Engle and $\mathrm{Ng}$ (1993). Figures 1 to 3 display the variance and covariance news impact surfaces from the estimates displayed in Table 2. Following Engle and Ng (1993) and Kroner and $\mathrm{Ng}$ (1998) each surface is evaluated in the region $\varepsilon_{j, t}=[-5,5]$ for $j=$ futures, cash. There are relatively few extreme outliers in the data, which suggests that some caution should be exercised in interpreting the news impact surfaces for larger values of $\varepsilon_{j, t}$. Despite this caveat, the asymmetry in variance and covariance is clear from each figure.

The returns and variances for the various hedging strategies are presented in table 3. The simplest approach, presented in the second column, is that of no hedge at all. In this case, the portfolio simply comprises a long position in the cash market. Such an approach is able to achieve significant positive returns in sample, but with a large variability of portfolio returns. Although none of the alternative strategies generate returns that are significantly different from zero, either in sample or out of sample, it is clear from columns 3-5 of table 3 that any hedge generates significantly less return variability than none at all. 
The naïve or cointegrating hedge, which takes one short futures contract for every spot unit, but does not allow the hedge to time-vary, generates a reduction in variance of the order of $80 \%$ in sample and nearly $90 \%$ out of sample relative to the unhedged position. Allowing the hedge ratio to be time-varying and determined from a symmetric multivariate GARCH model leads to a further reduction as a proportion of the unhedged variance of $5 \%$ and $2 \%$ on the in- and hold-out samples respectively. Allowing for an asymmetric response of the conditional variance to positive and negative shocks yields a very modest reduction in variance (a further $0.5 \%$ of the initial value) in sample, and virtually no change out of sample.

Figure 4 graphs the time varying hedge ratio from the symmetric and asymmetric MGARCH models. The optimal hedge ratio is never greater than 0.9586 futures contracts per index contract, with an average value of 0.8177 futures contracts sold per long index contract. The variance of the estimated optimal hedge ratio is 0.0019 . Moreover the optimal hedge ratio series obtained through the estimation of the asymmetric GARCH model appears stationary. An ADF test (see, for example, Fuller, 1976) of the null hypothesis $\beta_{t-1}^{*} \sim \mathrm{I}(1)$ was strongly rejected by the data $(\mathrm{ADF}=-5.7215,5 \%$ Critical value $=-2.8630$ ). The time varying hedge requires the sale (purchase) of fewer futures contracts per long (short) index contract. ${ }^{4}$

The optimal hedge ratio $\beta_{t-1}^{*}$ may be linked to the arrival of news to the market using (5) and the relevant futures price and covariance news impact surfaces. Evaluating $\beta_{t-1}^{*}$ in the range $\varepsilon_{j, t}=[-5,5]$ for $j=f u t u r e s$, cash as before gives us the response of the optimal hedge to news. Note that the surface is drawn under the assumption that the portfolio is long the stock index 
and the optimal hedge ratio is written in terms of the number of futures contracts to sell. A negative optimal hedge ratio thus implies the purchase of futures contracts. Figure 5 graphs the response of $\beta_{t-1}^{*}$ to news.

It is worth noting that $\beta_{t-1}^{*}$ responds far more dramatically to bad news about the cash market index than to news about the future price. Negative innovations in the cash price cause the optimal hedge ratio to increase in magnitude towards 1. Large positive innovations in the cash price suggest a negative hedge ratio. This might appear counter intuitive, however the surface is drawn holding past information constant. The implication of the asymmetry is that the hedge has very low value in bull market situations. In contrast, the cointegrating hedge implies that the hedging surface is a plane at $\beta_{t-1}^{*}=\bar{\beta}=1$. One possible interpretation of the better performance of the dynamic strategies over the naive hedge is that the dynamic hedge uses short run information, while the cointegrating hedge is driven by long run considerations. The performance evaluation in table 3 is in terms of one-day-ahead hedges. In the next section we use a new criterion to judge hedging over various horizons, including the one-day horizon.

\section{Evaluating Hedging Effectiveness by Calculating Minimum Capital Risk Requirements}

Ensuring that banks hold sufficient capital to meet possible future losses has been a topic of great import for regulators and risk managers in recent years. A very popular approach involves the calculation of the institution's value at risk (VaR) inherent in its trading book positions. VaR is an estimation of the probability of likely losses which might occur from 
changes in market prices from a particular securities position, and the minimum capital risk requirement (MCRR) is defined as the minimum amount of capital required to absorb all but a pre-specified percentage of these possible losses. We address an approach to the calculation of MCRRs which is similar in spirit to the approach adopted in many Internal Risk Management Models (IRMM), proposed by Hsieh (1993). ${ }^{5}$

Capital risk requirements are estimated for 1 day, 10 day, 30 day, 3 month and 6 month investment horizons by simulating the conditional densities of price changes, using Efron's (1982) bootstrapping methodology based upon the multivariate $\operatorname{GARCH}(1,1)$ model presented in equations (7) and (9), both with and without asymmetries, for comparison. The simulated errors are generated by drawing randomly, with replacement, from the standardised residuals and hence a path of future $\Delta Y_{t}$ 's can be generated, using the estimates of $\mu, \Gamma, \Pi, C_{0}, A_{11}$, and $B_{11}$ from the sample and multi-step ahead forecasts of $H_{t}$.

A securities firm wishing to calculate the VaR of a portfolio containing the cash and futures assets ${ }^{7}$ would have to simulate the price of the assets when it initially opened the position. To calculate the appropriate capital risk requirement, it would then have to estimate the maximum loss that the position might experience over the proposed holding period. ${ }^{6}$ For example, by tracking the daily value of a long cash and short futures position and recording its lowest value over the sample period, the firm can report its maximum loss for this particular simulated path of cash and futures prices. Repeating this procedure for 20,000 simulated paths generates an empirical distribution of the maximum loss. This maximum loss $(Q)$ is given by: 


$$
Q=\left(x_{0}-x_{1}\right)
$$

Where $x_{0}$ is the initial value of the portfolio and $x_{1}$ is the lowest simulated value of the portfolio (for a long futures position) or the highest simulated value (for a short futures position) over the holding period. We can express the maximum loss as a proportion of the initial value of the portfolio as follows:

$$
\frac{Q}{x_{0}}=\left(1-\frac{x_{1}}{x_{0}}\right)
$$

In this case, since $x_{0}$ is a constant, the distribution of $Q$ will depend on the distribution of $x_{1}$.

From expression (13), it can be seen that the distribution of $\frac{Q}{x_{0}}$ will depend on the distribution of $\frac{x_{1}}{x_{0}}$. Hence, the first step is to find the $5^{\text {th }}$ Quantile of $\operatorname{Ln}\left(\frac{x_{1}}{x_{0}}\right)$ :

$$
\frac{\operatorname{Ln}\left(\frac{x_{1}}{x_{0}}\right)-m}{S d}= \pm \alpha
$$

Where $\alpha$ is the $5^{\text {th }}$ Quantile from a standard normal distribution, $m$ is the Mean of $\operatorname{Ln}\left(\frac{x_{1}}{x_{0}}\right)$ and $S d$ is the Standard deviation of $\operatorname{Ln}\left(\frac{x_{1}}{x_{0}}\right)$. Crossmultiplying and taking the exponential,

$$
x_{1}=x_{0} \times \text { Exponential }[( \pm \alpha \times S d)+m]
$$

therefore

$$
Q=x_{0} \times\{1-\text { Exponential }[( \pm \alpha \times S d)+m]\}
$$


In this paper, we compare the MCRRs generated by the portfolios constructed using the hedge ratios derived from the models described above. The asymmetric multivariate GARCH model appears well specified and able to capture the salient features of the data. Given this, we now determine what would be an appropriate amount of capital to cover the cash and futures portfolio derived from the hedge ratio as implied by the model. In particular, we consider whether this portfolio minimises the need for capital, given that all such capital is tied up in an unproductive and unprofitable fashion.

The estimated minimum capital risk requirements are presented in tables 4 and 5 for each of the models, ignoring and allowing for asymmetries, respectively, and are given in units of index points ${ }^{8}$. Panel A of Tables 4 and 5 present the MCRR for a short hedge (long cash, short futures). While Panel B of the tables presents the results for a long hedge (long futures, short cash). The most important feature of the results is that any type of hedge, even a naïve hedge, is better than a naked exposure. Moreover, at short investment horizons, there are large gains to be made by allowing the hedge to vary over time. For example, the short hedge portfolio MCRR is 22.2 index points for a naïve hedge, but only 11.8 for a Multivariate GARCH hedge. The long hedge positions seem to be more risky overall over our out of sample period, generating higher values at risk than the corresponding short hedges.

The gain from the use of an asymmetric model, as opposed to a constrained symmetric model, which does not allow good and bad news to effect returns differently, is large at short time horizons. For example, for the symmetric time-varying short hedge, the portfolio MCRR is 11.8, while modelling the asymmetries reduces this to 2.0. However, the benefit of these 
more complex asymmetric and time-varying hedges, and moreover, the benefits of hedging per se, are considerably reduced as the time horizon is extended beyond one month. For example, the MCRR for a long hedge calculated using asymmetric MGARCH is less than $10 \%$ of that using no hedge at the one day horizon, but rises to more than $25 \%$ over a 6 month hedging period. This result is in agreement with the findings of Lin et al. (1994).

\section{Conclusions}

This paper sought to advance the extant literature in this field by considering the impact of asymmetries on the hedging of stock index positions using financial futures contracts ${ }^{9}$. We found that asymmetric models, which allow positive and negative price innovations to affect volatility forecasts differently, yielded improvements in forecast accuracy in sample, but not out of sample, when evaluated using the traditional variance of realised returns metric.

The paper also demonstrated how such hedging methodologies could be evaluated in a modern risk management context, using a technique based on the estimation of value at risk. Our primary finding was that allowing for asymmetries led to considerably reduced portfolio risk at the shortest forecasting horizons, and modest benefits when the duration of the hedge was increased.

Our results have at least two important implications for those financial market transactors who wish to reduce their exposure to risk using futures contracts, and for further research in this area. First, hedge ratios which are 
determined taking into account asymmetries in volatility are expected, in general, to be more effective than those which do not. Second, since recent changes in legislation in Europe have allowed market risk to be determined using value at risk technologies under the second EC Capital Adequacy Directive (CAD II), it is surely desirable for hedgers to measure the risk inherent in their hedged portfolios in a similar fashion. Such procedures are already now in widespread use in Europe as well as the US. The value at risk approach is (or soon will be) used to assess the risk of the books of securities firms as a whole. The use of traditional methods for assessing hedging effectiveness, such as portfolio return variances, could be incompatible with, and give very different results to, those based on value at risk methods. 


\section{Footnotes}

* This paper was written while the second author was on study leave at the ISMA Centre, Department of Economics, The University of Reading. The development of this paper benefited from comments by the anonymous referees and discussions with Salih Neftci, Simon Burke and Peter Summers. The responsibility for any errors or omissions lies solely with the authors.

${ }^{1}$ Note that we are not requiring at this stage that the hedge ratio, $\beta_{t-1}$, be timevarying, but rather that it is determined using information to time $t-1$.

${ }^{2}$ Since these contracts expire 4 times per year - March, June, September and December - to obtain a continuous time series we use the closest to maturity contract unless the next closest has greater volume, in which case we switch to this contract.

${ }^{3}$ The reason for this is that the minimum price movement (known as tick) for the futures contract is $£ 12.50$ i.e. a change of 0.5 in the index.

4 Although, of course, a time-varying hedge may result in considerably increased transactions costs in the likely event that such a hedge requires daily adjustments of the futures position. We therefore cannot state categorically that the time-varying hedge would be cheaper.

5 See also Brooks et al. (2000) for a more detailed description of this methodology and issues in its implementation. 
${ }^{6}$ See Dimson and Marsh (1997) for a discussion of a number of potential issues which a financial institution may face when calculating appropriate levels of capital for multiple positions during periods of stress.

${ }^{7}$ The current BIS rules state that the MCRR should be the higher of the: (i) average MCRR over the previous 60 days or (ii) the previous trading days' MCRR.

${ }^{8}$ See section 3 above. Although Hsieh (1993) and Brooks et al. (2000) measure MCRRs as a proportion of the initial value of the position, this is not sensible in our case since by definition an appropriately hedged portfolio will have a zero value.

${ }^{9}$ Although the methodology could, of course, be equally applied to hedging a position in any financial asset using futures contracts. 


\section{References}

Baillie, R.T. and Myers, R.J. 1991. Bivariate GARCH estimation of the optimal commodity futures hedge. Journal of Applied Econometrics 6 (April): 109-124.

Bollerslev, T., Engle, R.F. and Wooldridge, J.M. 1988. A capital asset pricing model with time-varying covariances. Journal of Political Economy 96 (February): 116-31.

Brooks, C., Clare, A.D. and Persand, G. 2000 A word of caution on calculating market-based capital risk requirements. Journal of Banking and Finance forthcoming.

Cechetti, S.G., Cumby, R.E., Figlewski, S. 1988. Estimation of optimal futures hedge. Review of Economics and Statistics 70 (November): 623-630.

Dimson, E. and P. Marsh 1997. Stress tests of capital requirements. Journal of Banking and Finance. 21 (July): 1515-1546.

Efron, B. 1982. The Jackknife, the Bootstrap, and Other Resampling Plans, Philadelphia, PA: Society for Industrial and Applied Mathematics.

Engle, R.F. and Granger, C.W.J. 1987. Cointegration and error correction: representation, estimation and testing. Econometrica 55 (March): 25176. 
Engle, R.F. and Ng, V. 1993. Measuring and testing the impact of news on volatility. Journal of Finance, 48 (December): 1749-1778.

Engle, R.F. and Kroner, K. 1995. Multivariate simultaneous generalised ARCH. Econometric Theory, 11 (March), 122-150.

Fuller, W.A. 1976. Introduction to Statistical Time Series Wiley, N.Y.

Garcia, P., Roh, J-S, and Leuthold, R.M. 1995. Simultaneously determined, time-varying hedge ratios in the soybean complex. Applied Economics 27 (November): 1127-1134.

Ghosh, A. 1993. Cointegration and error correction models: Intertemporal causality between index and futures prices. Journal of Futures Markets 13 (April): 193-198.

Glosten, L.R., Jagannathan, R. and Runkle, D.E. 1993. On the relation between the expected value and the volatility of the nominal excess return on stocks. The Journal of Finance 48 (December): 1779-1801.

Hodgson, A. and Okunev, J. 1992. An alternative approach for determining hedge ratios for futures contracts. Journal of Business Finance and Accounting 19 (January): 211-224 
Hsieh, D.A. 1993. Implications of non-linear dynamics for financial risk management. Journal of Financial and Quantitative Analysis 28 (March): 41-64.

Johansen, S. 1988. Statistical analysis of cointegration vectors Journal of Economic Dynamics and Control 12, 231-254.

Kroner, K.F., and Ng, V.K. 1998. Modelling asymmetric co-movements of asset returns. Review of Financial Studies, 11 (Winter): 817-844.

Kroner, K.F. and Sultan, J. 1991. Exchange rate volatility and time-varying hedge ratios. In Rhee, S.G. and Chang, R.P. (eds.) Pacific Basin Capital Markets Research. Elsevier, North Holland.

Lien, D. and Luo, X. 1993. Estimating multiperiod hedge ratios in cointegrated markets. Journal of Futures Markets 13 (December): 909920.

Lin, J.W., Najand, M., and Yung, K. 1994. Hedging with currency futures: OLS versus GARCH. Journal of Multinational Financial Management 4 (January): 45-67.

Myers, R.T. and Thompson, S.R. 1989. Generalised optimal hedge ratio estimation. American Journal of Agricultural Economics 71 (November): 858-867. 
Park, T.H. and Switzer, L.N. 1995. Bivariate GARCH estimation of the optimal hedge ratios for stock index futures: A note. Journal of Futures Markets 15 (February): 61-67.

Strong, R.A. and Dickinson, A. 1994. Forecasting better hedge ratios. Financial Analysts Journal. 50 (January-February): 70-72.

Sutcliffe, C. 1997. Stock Index Futures: Theories and International Evidence. Second Edition, Thompson Business Press, London. 
Table 1: Summary Statistics and Cointegration Tests

Panel A: Summary Statistics for the data

\begin{tabular}{ccccc}
\hline \hline & & $\mathrm{ADF}(\mu)$ & & $\mathrm{ADF}$ \\
$F_{t}$ & & -1.7028 & & 1.9982 \\
$C_{t}$ & & -1.0082 & & 2.2269 \\
\hline Series & Mean & Variance & Skewness & Excess \\
& & & & Kurtosis \\
& & & & 25.3160 \\
$\Delta F_{t}$ & 0.0392 & 1.1424 & -1.6081 & 25.6852 \\
$\Delta C_{t}$ & 0.0389 & 0.8286 & -1.6602 & \\
\hline
\end{tabular}


Panel B: Engle Granger Cointegration Tests

\begin{tabular}{|c|c|c|c|}
\hline \multicolumn{4}{|c|}{$\mathrm{F}_{\mathrm{t}}$ as dependent variable } \\
\hline$\phi_{0}$ & $\phi_{1}$ & $\operatorname{ADF}(\mu)$ & $\mathrm{ADF}$ \\
\hline-0.0327 & 1.0031 & -8.3846 & -8.3859 \\
\hline$(0.0039)$ & $(0.0005)$ & & \\
\hline \multicolumn{4}{|c|}{$C_{t}$ as dependent variable } \\
\hline$\gamma_{0}$ & $\gamma_{1}$ & $\operatorname{ADF}(\mu)$ & $\mathrm{ADF}$ \\
\hline 0.0386 & 0.9961 & -8.4026 & -8.4039 \\
\hline$(0.0039)$ & $(0.0005)$ & & \\
\hline \multicolumn{4}{|c|}{ Panel C: Johansen Cointegration Tests } \\
\hline & $\lambda_{M}$ & $\lambda_{T}$ & \\
\hline$r=0$ & 91.75 & 92.58 & \\
\hline $\mathrm{r}=1$ & 0.83 & 0.83 & \\
\hline \multicolumn{4}{|c|}{ Likelihood Ratio Tests } \\
\hline$H_{0}: \beta^{\prime}=[-1,1]$ & $H_{0}: \alpha=[1,0]$ & \multicolumn{2}{|c|}{$H_{0}: \beta^{\prime}=[-1,1] \mid \alpha=[1,0]$} \\
\hline 4.4800 & 0.06900 & \multicolumn{2}{|c|}{5.51} \\
\hline$[0.0300]$ & {$[0.4000]$} & \multicolumn{2}{|c|}{$[0.06]$} \\
\hline
\end{tabular}


Table 2: Estimates of the Multivariate Asymmetric GARCH Model

Conditional Mean Equations

$$
\begin{aligned}
& \Delta Y_{t}=\mu+\sum_{i=1}^{4} \Gamma_{i} \Delta Y_{t-i}+\Pi v_{t-1}+\varepsilon_{t} \\
& Y_{t}=\left[\begin{array}{c}
F_{t} \\
P_{t}
\end{array}\right] ; \mu=\left[\begin{array}{l}
\mu_{F} \\
\mu_{C}
\end{array}\right] ; \Gamma_{i}=\left[\begin{array}{cc}
\Gamma_{i, F}^{(F)} & \Gamma_{i, C}^{(F)} \\
\Gamma_{i, F}^{(C)} & \Gamma_{i, C}^{(C)}
\end{array}\right] ; \pi=\left[\begin{array}{l}
\pi_{F} \\
\pi_{C}
\end{array}\right] ; \varepsilon_{t}=\left[\begin{array}{l}
\varepsilon_{F, t} \\
\varepsilon_{C, t}
\end{array}\right]
\end{aligned}
$$$$
\Gamma_{1}=\left[\begin{array}{ll}
-0.0078 & -0.0225 \\
(0.0060) & (0.0072) \\
0.0759 & 0.0257 \\
(0.0053) & (0.0061)
\end{array}\right] \quad \Gamma_{2}=\left[\begin{array}{ll}
-0.1499 & 0.1399 \\
(0.0089) & (0.0110) \\
0.0272 & -0.0238 \\
(0.0080) & (0.0092)
\end{array}\right]
$$$$
\Gamma_{3}=\left[\begin{array}{ll}
-0.1225 & 0.1083 \\
(0.0111) & (0.0149) \\
-0.0352 & 0.0293 \\
(0.0114) & (0.0117)
\end{array}\right]
$$$$
\Gamma_{4}=\left[\begin{array}{ll}
-0.0699 & 0.0084 \\
(0.0227) & (0.0256) \\
0.0141 & -0.0032 \\
(0.0182) & (0.0232)
\end{array}\right]
$$

$$
\mu=\left[\begin{array}{l}
0.0518 \\
(0.0057) \\
0.0523 \\
(0.0050)
\end{array}\right]
$$

$$
\Pi=\left[\begin{array}{c}
0.1636 \\
(0.0195) \\
-0.1719 \\
(0.0142)
\end{array}\right]
$$

$\kappa \quad 6.0606$

$(0.2454)$ 
Table 2 Continued:

Estimates of the Multivariate Asymmetric GARCH Model

\begin{tabular}{|c|c|c|c|c|c|c|}
\hline \multicolumn{7}{|c|}{ Residual Diagnostics } \\
\hline & Mean & Variance & Skewness & $\begin{array}{l}\text { Excess } \\
\text { Kurtosis }\end{array}$ & $Q(10)$ & $Q^{2}(10)$ \\
\hline$\varepsilon_{F, t}$ & -0.0023 & 1.0790 & $\begin{array}{l}-0.9077 \\
{[0.0000]}\end{array}$ & $\begin{array}{l}12.7237 \\
{[0.0000]}\end{array}$ & $\begin{array}{l}13.3361 \\
{[0.2055]}\end{array}$ & $\begin{array}{c}2.1991 \\
{[0.9946]}\end{array}$ \\
\hline$\varepsilon_{C, t}$ & -0.0079 & 1.0438 & $\begin{array}{c}0.4578 \\
{[0.0000]}\end{array}$ & $\begin{array}{c}5.9459 \\
{[0.0000]}\end{array}$ & $\begin{array}{l}12.0461 \\
{[0.2820]}\end{array}$ & $\begin{array}{c}7.6730 \\
{[0.6607]}\end{array}$ \\
\hline
\end{tabular}

Notes: Standard errors displayed as (.). Marginal significance levels displayed as [.]. $Q(10)$ and $Q^{2}(10)$ are are Ljung_Box tests for tenth order serial correlation in $z_{j, t}$ and $z_{j, t}^{2}$ respectively for $j=F, C$. 
Table 2 Continued: Estimates of the Multivariate Asymmetric GARCH Model

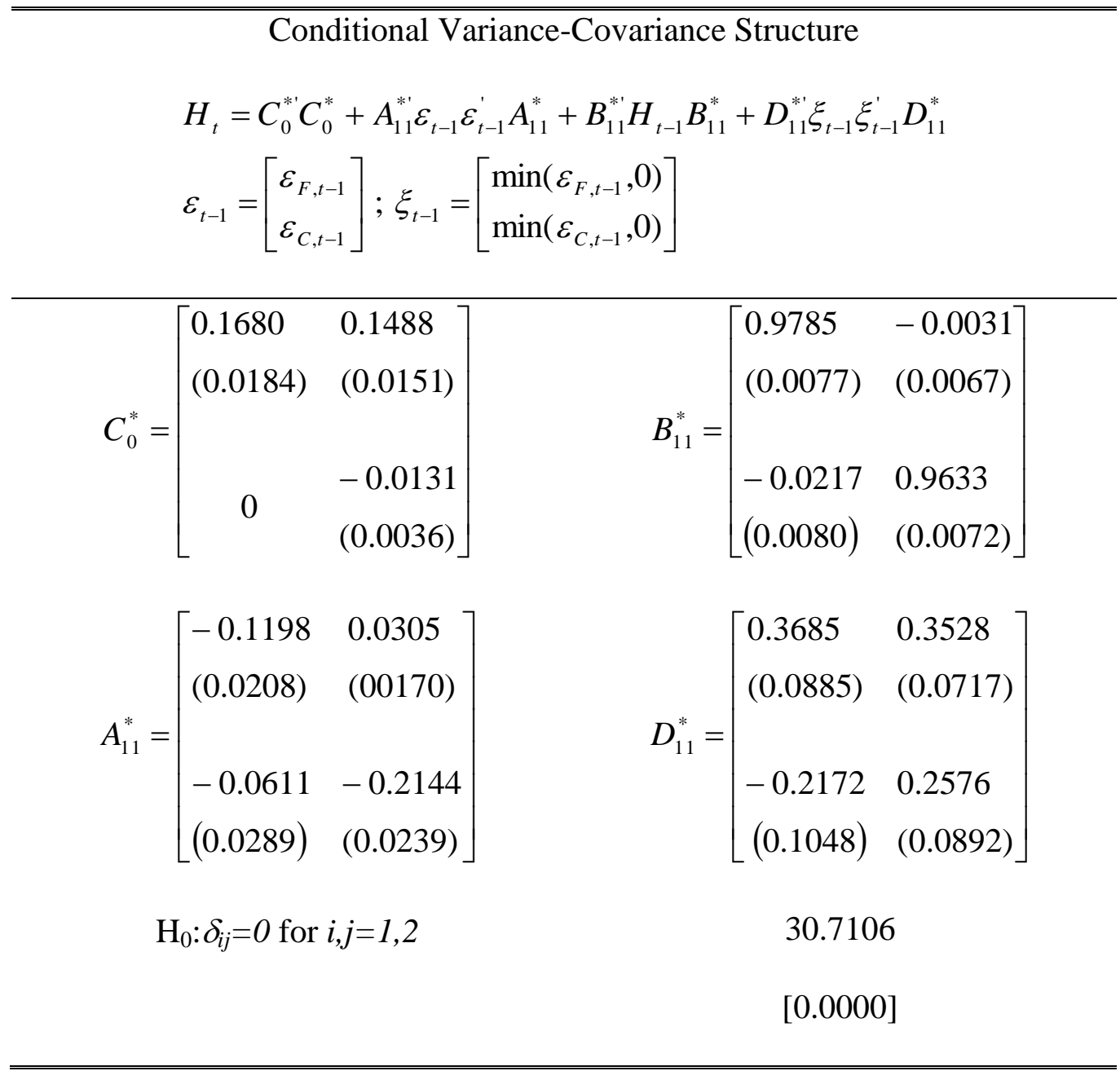




\section{In Sample}

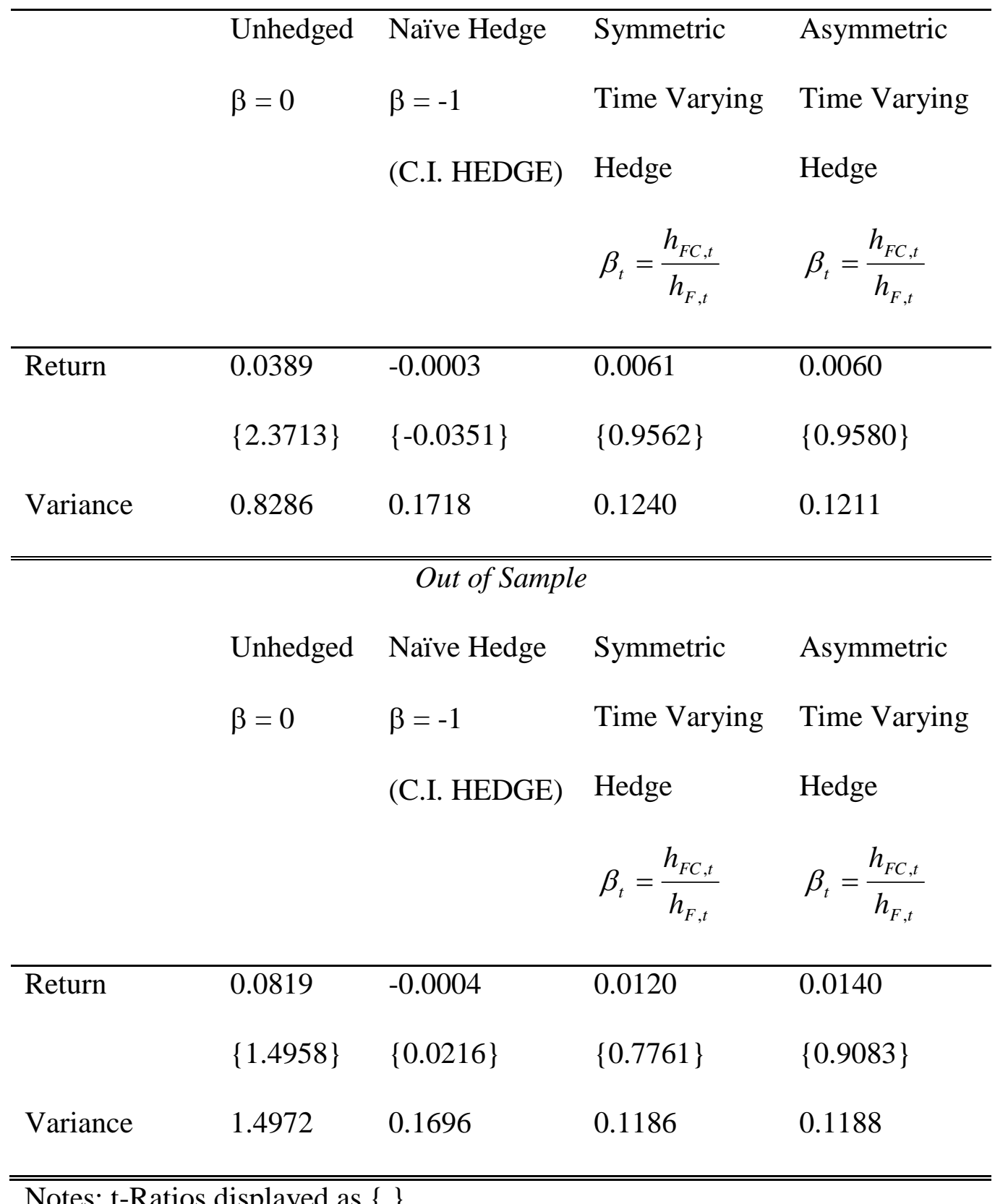

Notes: t-Ratios displayed as $\{$. 
Table 4: MCRR Estimates - Symmetric Hedging Models

Panel A: Long Cash and Short Futures

\begin{tabular}{cccc}
\hline \hline Days & Unhedged & Nä̈ve Hedge & Time-Varying \\
& & & Hedge \\
\hline 1 & 27.851 & 22.175 & 11.763 \\
10 & 211.210 & 99.819 & 96.308 \\
20 & 234.215 & 197.217 & 124.214 \\
30 & 358.872 & 238.632 & 167.297 \\
60 & & & 245.312 \\
90 & 411.058 & 425.661 & 293.263 \\
180 & 513.368 & 499.756 & 378.451 \\
& & & \\
\hline \hline
\end{tabular}


Table 4: MCRR Estimates - Symmetric Hedging Models

Panel B: Short Cash and Long Futures

\begin{tabular}{cccc}
\hline \hline Days & Unhedged & Nä̈ve Hedge & Time-Varying \\
& & & Hedge \\
\hline 1 & 49.525 & 25.783 & 16.294 \\
10 & 260.847 & 147.355 & 84.773 \\
20 & 385.323 & 217.493 & 176.856 \\
30 & & & 216.965 \\
60 & 414.618 & 258.481 & 290.489 \\
90 & 667.067 & 320.512 & 348.487 \\
180 & 943.051 & 567.666 & 537.951 \\
& & & \\
\hline \hline
\end{tabular}


Table 5: MCRR Estimates - Asymmetric Hedging Models

Panel A: Long Cash and Short Futures

\begin{tabular}{|c|c|c|c|}
\hline Days & Unhedged & Nä̈ve Hedge & $\begin{array}{c}\text { Time-Varying } \\
\text { Hedge }\end{array}$ \\
\hline 1 & 20.792 & 2.356 & 2.003 \\
\hline 10 & 196.812 & 83.475 & 74.268 \\
\hline 20 & 237.567 & 182.852 & 96.776 \\
\hline 30 & 370.988 & 228.123 & 155.325 \\
\hline 60 & 416.221 & 416.632 & 229.875 \\
\hline 90 & 529.219 & 484.566 & 292.852 \\
\hline 180 & 746.852 & 549.633 & 354.685 \\
\hline
\end{tabular}


Table 5: MCRR Estimates - Asymmetric Hedging Models

Panel B: Short Cash and Long Futures

\begin{tabular}{cccc}
\hline \hline Days & Unhedged & Nä̈ve Hedge & Time-Varying \\
& & & Hedge \\
\hline 1 & 46.852 & 8.511 & 3.321 \\
10 & 228.562 & 120.256 & 83.523 \\
20 & 415.785 & 176.118 & 105.963 \\
30 & 507.952 & 213.963 & 153.523 \\
60 & & & 221.541 \\
90 & 717.633 & 315.784 & 273.965 \\
180 & 1004.159 & 644.935 & 381.522 \\
& & & \\
\hline \hline
\end{tabular}




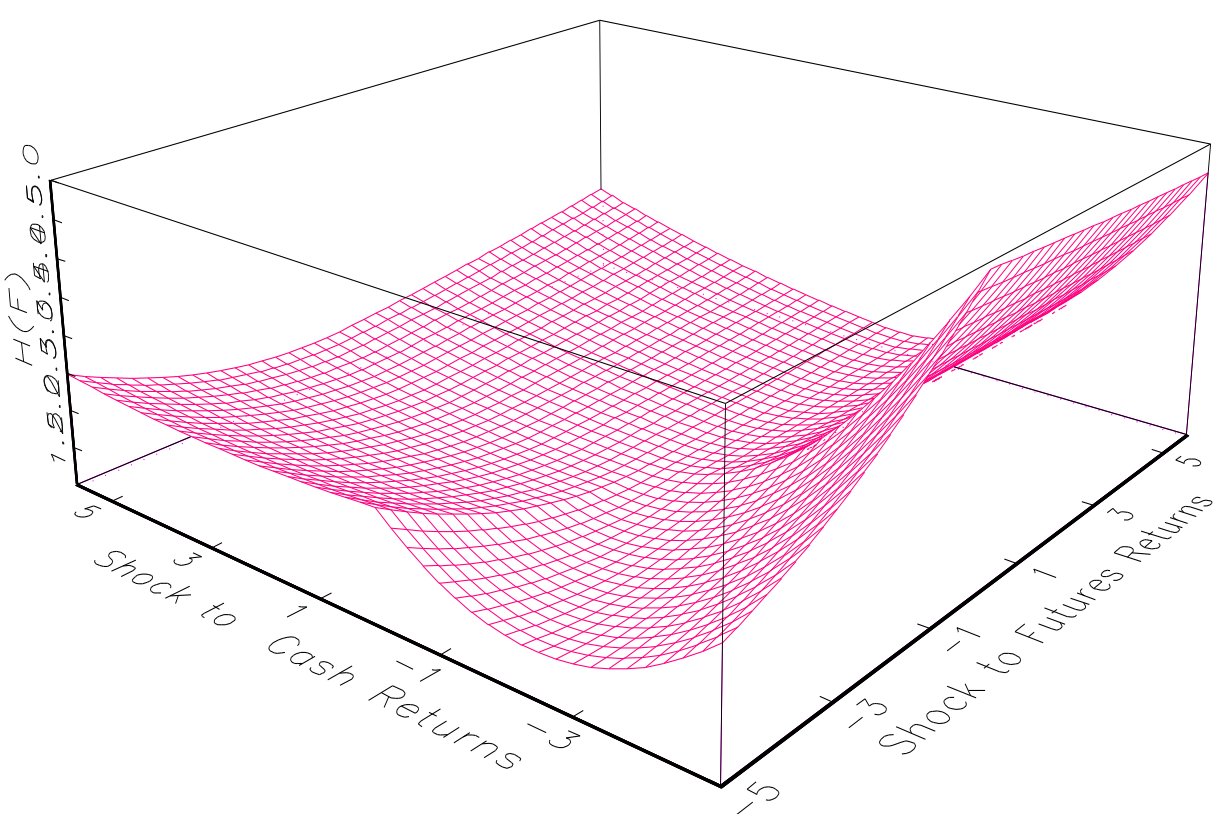

Figure 1: News Impact Surface for Futures Market Volatility 


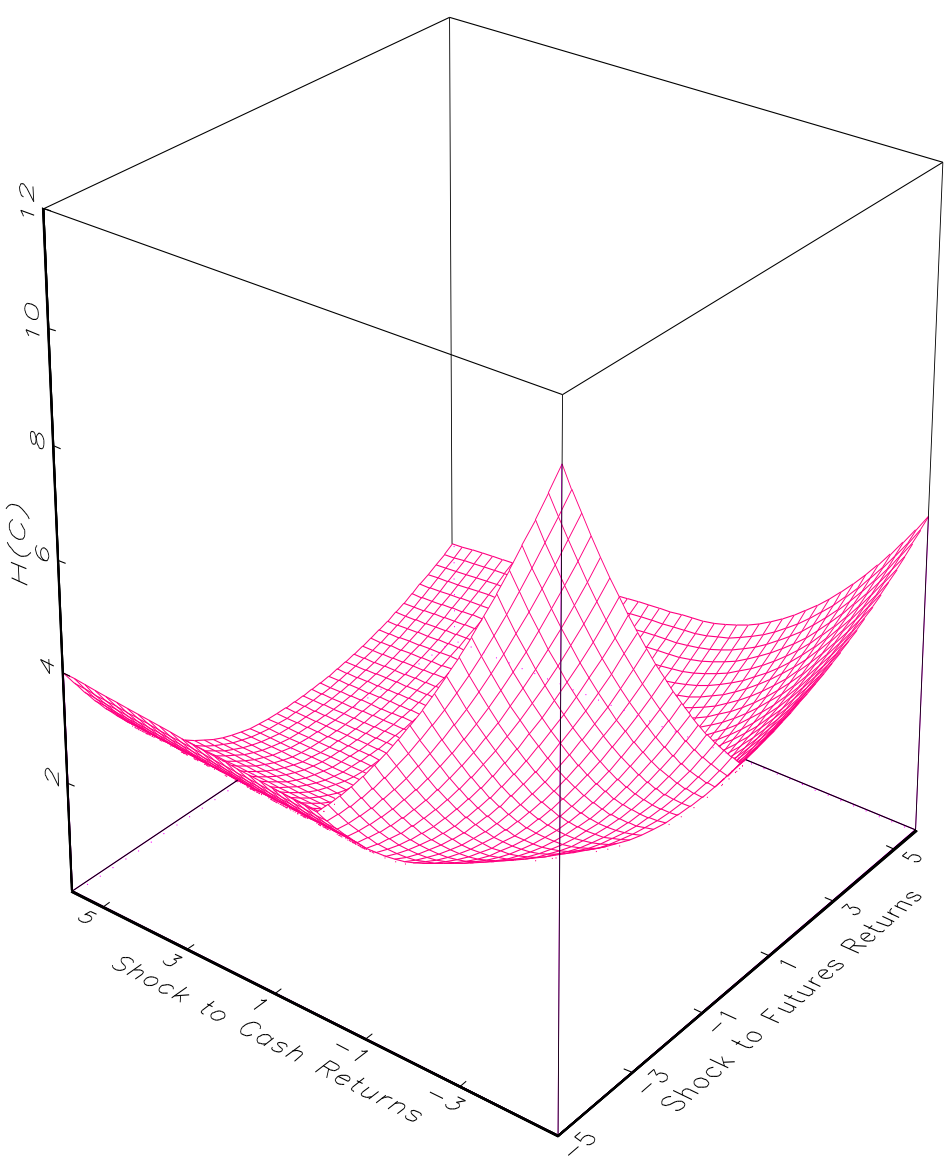

Figure 2: News Impact Surface for Cash Market Volatility 


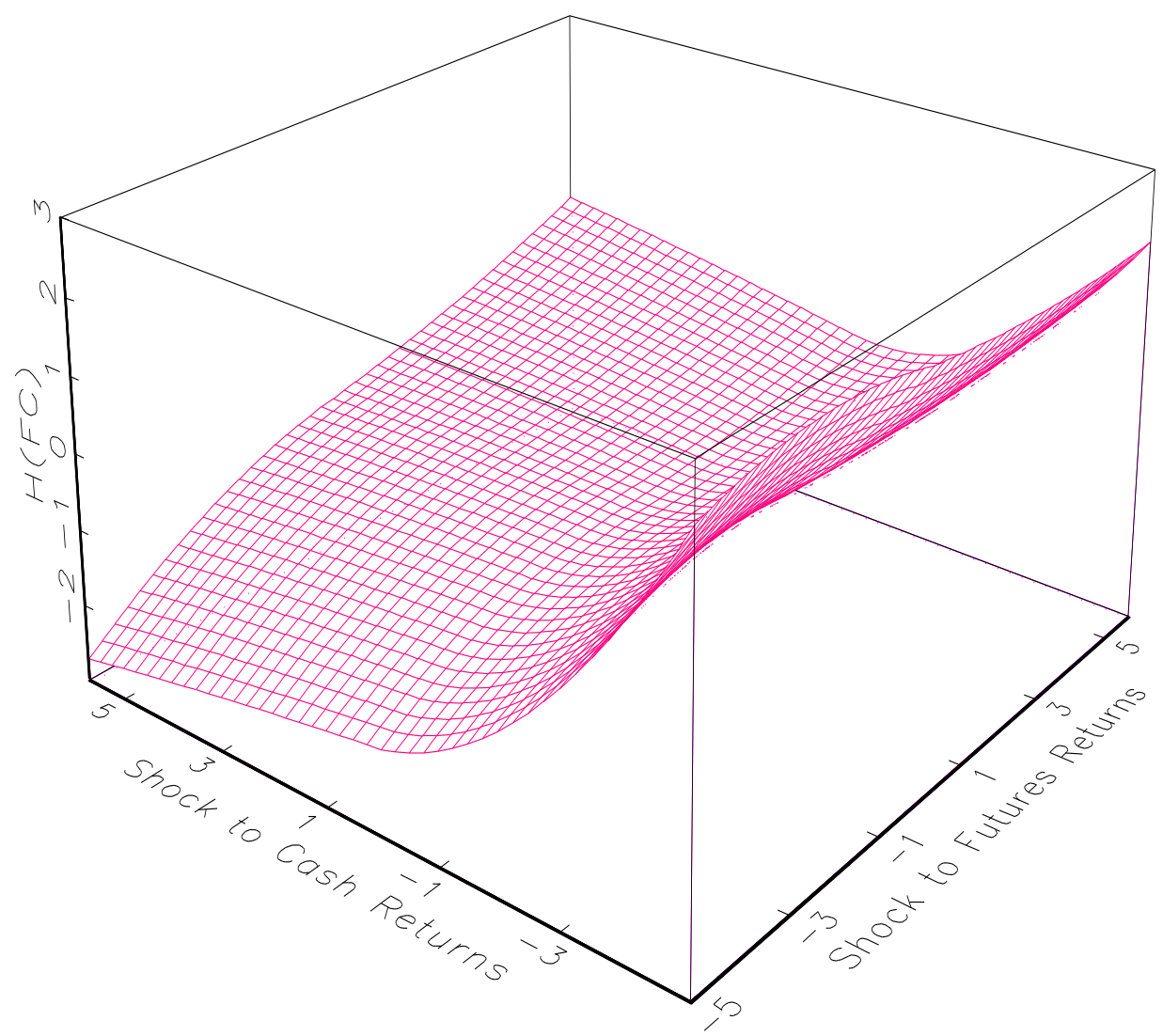

Figure 3: Covariance News Impact Surface 


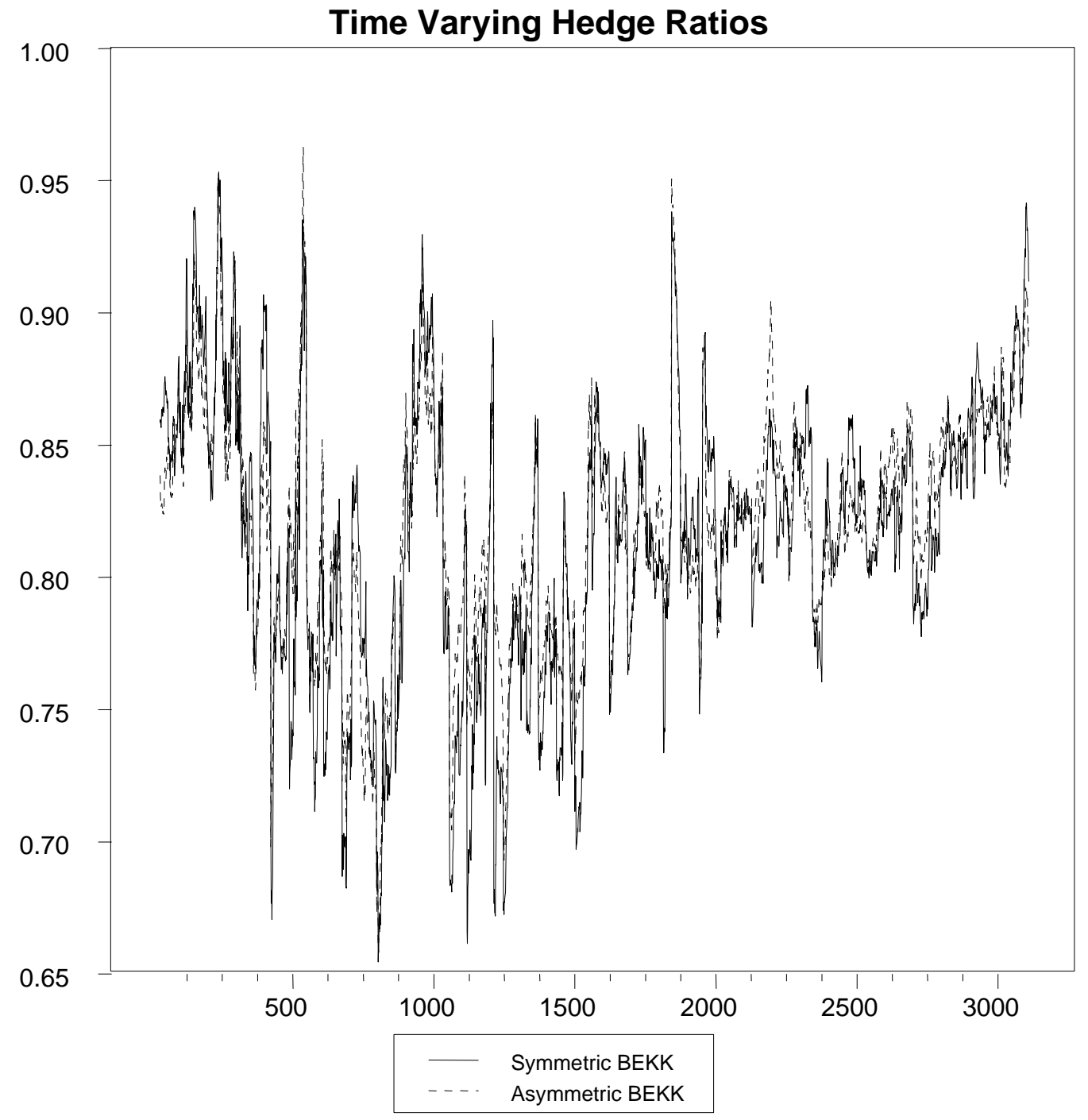

Figure 4: The optimal dynamic hedge ratio, $\beta_{t-1}^{*}$ 


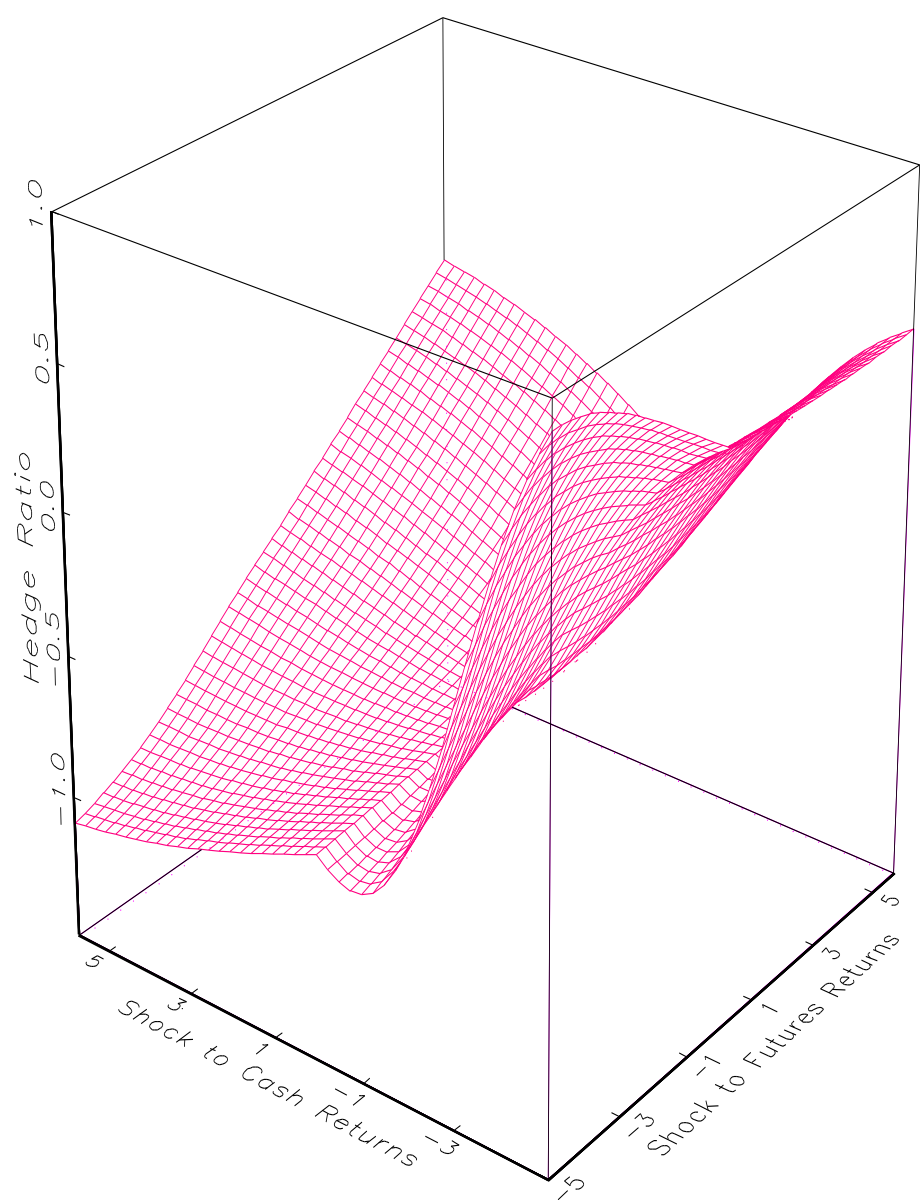

Figure 5: Hedging Surface: The response of $\beta_{t}^{*}$ to News 